\title{
Quando uma vila do Império Português pede para tornar-se cidade (Moçambique, 1800)
}

\section{When a village of the Portuguese Empire requests to become a city (Mozambique, 1800)}

\author{
Ana Paula Wagner
}

\begin{abstract}
Resumo
No ano de 1800 foi encaminhado para Lisboa um pedido de elevação da vila de Moçambique ao estatuto de cidade. A documentação produzida em razão desta solicitação revelou um quadro complexo, tratando-se de uma ação coordenada por distintas instâncias de poder domiciliadas na sede do governo da África Oriental Portuguesa. A ênfase na escrita do governador-geral, dos membros da câmara e do religioso nos mostraram, ao mesmo tempo, as suas expectativas quanto à mudança do estatuto da vila, as suas representações de cidade e as formas como cada um desses sujeitos se relacionava com as diferentes esferas integrantes do Império Português. Nesse sentido, procuramos realizar um exercício de compreensão de um tema (elevação de uma vila à categoria de cidade) dentro de escalas de análise que transitaram em termos locais (vila de Moçambique) e em um contexto global, delimitado pelas dinâmicas do Império Português.
\end{abstract}

Palavras-chave: Vila de Moçambique; Cidade; Império Português.

\begin{abstract}
In 1800 a request was sent to Lisbon for the elevation of the town of Mozambique to the status of city. The documentation produced as a result of this request revealed a complex situation, being an action coordinated by different authorities of power residing in the headquarters of the Government of East Africa. The emphasis on the writings of the governor-general, the members of the chamber and the clergy showed us at the same time their expectations regarding the change of the status of the village, their representations of the city and the ways in which each of these subjects related to the different spheres of the Portuguese Empire. In this sense, we try to carry out an exercise in understanding a theme (elevation of a village to the category of city) within scales of analysis that have transited in local terms (village of Mozambique) and in a global context, delimited by the dynamics of the Portuguese Empire.
\end{abstract}

Key words: Mozambique; City; Portuguese Empire.

\footnotetext{
* Doutora em História pela UFPR. Professora do Departamento de História da Universidade Estadual do Centro-Oeste, campus Irati (UNICENTRO-PR).E-mail: anapwagner@gmail.com
} 
Jaques Revel, na apresentação da obra Jogos de Escalas: a experiência da microanálise, argumenta que a análise de uma realidade social pode variar conforme a escala de observação escolhida pelo pesquisador. ${ }^{1}$ Nessa direção, o conceito de Império Português permite que o historiador, ao mesmo tempo em que se propõe a realizar um estudo local (regional, ou nacional), não perca de vista o contexto no qual a realidade social em foco está inserida. Ou seja, trata-se de um exercício muito salutar no processo de construção do conhecimento histórico. ${ }^{2}$

Em grande medida, a noção de Império Português possibilita iluminar e discutir a complexidade formada pelo conjunto de diferentes realidades sociais e de espaços geográficos submetidos ao rei de Portugal, durante a época moderna. A integração de diferentes objetos de trabalho em um quadro mais amplo permite o estabelecimento de comparações, identificação de semelhanças e de diferenças e a ligação das múltiplas partes em um todo. De maneira geral, esta é uma das tendências de estudos que tem o conceito de Império Português como interlocutor. ${ }^{3}$

Ao longo da história do Império Português, a instalação de vilas e cidades constituiu um importante capítulo dos processos de expansão e, sobretudo, de consolidação da presença lusa nos distintos domínios ultramarinos. Em razão do seu caráter pluricontinental, com territórios nas Ilhas de Açores e

\footnotetext{
${ }^{1}$ REVEL, Jaques. "Apresentação" In Jogos de Escalas: a experiência da microanálise. Rio de Janeiro, Editora Fundação Getúlio Vargas, 1998, p. 7-14.

${ }^{2}$ Como o próprio Jaques Revel explica, a forma como escolhemos expor nossas pesquisas já informa muito sobre a maneira como construímos nosso objeto e como fizemos a interpretação deste. REVEL, Jaques. "Microanálise e construção do social" In Jogos de Escalas... op. cit., p. 15-38, p. 38.

${ }^{3}$ Podemos mencionar como representantes dessa tendência historiográfica as obras de: BETHENCOURT, Francisco; CHAUDHURI, Kirti (Coord.). História da Expansão Portuguesa. O Brasil na Balança do Império. (volume III). Navarra, Círculo de Leitores, 1998; BETHENCOURT, Francisco et al (Dir.). A expansão marítima portuguesa, 1400-1800. Lisboa, Edições 70, 2010; BICALHO, Maria Fernanda; FERLINI, Vera Lúcia Amaral (Orgs.). Modos de Governar. Idéias e práticas políticas no Império Português, séculos XVI a XIX. São Paulo, Alameda, 2005; BOXER, Charles R. $O$ império colonial português: 1415-1825. Lisboa, Edições 70, 1981; DISNEY, Anthony R.. História de Portugal e do Império Português. Vol 1. Lisboa, Guerra e Paz, 2010; FRAGOSO, João; SAMPAIO, Antonio Carlos Jucá de (Orgs.). Monarquia pluricontinental e a governanç̧a da terra no ultramar atlântico luso: séculos XVI-XVIII. Rio de Janeiro, Mauad X, 2012; FRAGOSO, João; GOUVÊA, Maria de Fátima (Orgs). Na trama das redes: política e negócios no Império Português, séculos XVI-XVIII. Rio de Janeiro, Civilização Brasileira, 2010; FRAGOSO, João et al. (Orgs.). Nas rotas do Império: eixos mercantis, tráfico e relações sociais no mundo português. Vitória, Edufes; Lisboa, IICT, 2006; FRAGOSO, João; BICALHO, Maria Fernanda; GOUVÊA, Maria de Fátima (Orgs). 0 antigo regime nos trópicos: a dinâmica imperial portuguesa (séculos XVI - XVIII). Rio de Janeiro, Civilização Brasileira, 2001; FURTADO, Júnia F. (Org.). Diálogos oceânicos; Minas Gerais e as novas abordagens para uma história do Império Ultramarino Português. Belo Horizonte, Editora da UFMG, 2001; HESPANHA, António Manuel (Coord.). História de Portugal. O Antigo Regime (1620-1807). Lisboa, Editorial Estampa, 1998; RUSSELL-WOOD, A. J. R. Um mundo em movimento: os portugueses na África, Ásia e América (1415-1808). Algés, Difel, 1998; SUBRAHMANYAM, Sanjay. O Império Asiático Português (1500-1700). Uma história política e económica. Lisboa, Difel, 1995; THOMAZ, Luís Felipe F.R. De Ceuta a Timor. Lisboa, Difel, 1994.
} 
Madeira, na América, África e Ásia, além das diferenças geográficas, políticas, econômicas, sociais e culturais, podemos considerar que foi necessária a criação e a adaptação de uma série de mecanismos para garantir a longevidade do empreendimento ao decorrer dos séculos.

No mundo português apenas a Coroa, na figura do rei, tinha a prerrogativa de criar cidades, concedendo-lhes determinados foros e regalias. ${ }^{4}$ Aroldo de Azevedo, no clássico Vilas e cidades do Brasil colonial, argumenta que a concessão do título de cidade parece não ter seguido uma lógica de critérios específicos, como a importância demográfica, social ou econômica de determinado território. Pelo contrário, segundo o autor, muitas vezes traduzia "um simples galardão, mera honraria, que circunstâncias de momento poderiam justificar". ${ }^{5}$ Todavia, ainda que o estatuto de cidade não fosse atribuído em razão de algum tipo de destaque econômico ou político, esse era um título almejado pelos súditos de determinados territórios que integravam o Império Português.

Como já indicado, as vilas e as cidades tinham papeis fundamentais no processo de materialização da presença lusa nos espaços ultramarinos. No que diz respeito às vilas, ela implicava na instalação de um aparato institucional através das câmaras municipais. Os vereadores e juízes, como membros na câmara, detinham funções legislativas, executivas e judiciárias. ${ }^{6}$ Em certo sentido, pode-se falar de uma autonomia política e administrativa experimentada pelo município, ainda que dentro da hierarquia mais ampla do Império. ${ }^{7}$

Em relação às cidades, Beatriz Piccolotto S. Bueno, em estudo sobre a importância de vilas e cidades na formação da capitania de São Paulo, argumenta

\footnotetext{
${ }^{4}$ RUSSEL-WOOD. A. J. R. “Centros e Periferias no Mundo Luso-Brasileiro, 1500-1808” In Revista Brasileira de História. São Paulo, 1988, Vol. 18, no. 36. Os municípios nos territórios ultramarinos significavam a transposição de instituições e modelos metropolitanos. Todavia, a bibliografia referente à temática assinala a existência de um processo de adaptação às especificidades de cada conquista. Ver SANTOS, Antonio Cesar de Almeida. "Algumas observações sobre a ação política pombalina. Instruções de governo para garantirem a 'multiplicação de povoações civis e decorosas' na América portuguesa" In VI Jornada Setecentista: Conferências e Comunicações. Curitiba, Aos Quatro Ventos/CEDOPE, 2006, p. 149-170.

${ }^{5}$ AZEVEDO, Aroldo de. "Vilas e cidades do Brasil colonial - ensaio de geografia urbana retrospectiva" In Terra Livre, 1992, 10, p. 23-78, p. 69-70. Aroldo de Azevedo cita como exemplo as cidades Filipéia, Cabo Frio e Oeiras, todas na América Portuguesa.

${ }^{6}$ Ver BICALHO, Maria Fernanda. A cidade e o Império: o Rio de Janeiro no século XVIII. Rio de Janeiro, Civilização Brasileira, 2003; especialmente o capítulo "Centro e Periferia: as Câmaras Municipais no Ultramar". Para esta autora, "a formação do Império se deu por meio da trasladação de uma série de mecanismos políticos, jurídicos e administrativo da metrópole para as mais recônditas regiões do globo, tanto no Oriente como Ocidente", ainda que tivesse sido necessário fazer adaptações do aparato institucional às diversidades socioculturais encontradas nos distintos territórios da América, África e Ásia (p. 367).

${ }^{7}$ Sobre a constituição de hierarquias no Império Português, ver HESPANHA, António Manuel; SANTOS, Maria Catarina. "Os poderes num império oceânico" In História de Portugal. v. 4, o Antigo Regime (1620-1807). Lisboa, Editorial Estampa, 1998, p. 351-366.
} 
que estas compreendiam "prolongamentos do aparelho estatal, braços da Coroa, no reino ou nas distantes conquistas ultramarinas". ${ }^{8}$ Para essa afirmação, a autora baseou-se nas Ordenações, segundo a qual as cidades consistiam em "capitais" - "cabeça, princípio, \& fonte, donde outras cousas se encerram".

Em termos práticos, no que se refere ao gerenciamento administrativo da população e do território, não havia grandes diferenças do aparato institucional de uma vila ou cidade. Porém, ainda que não ocorresse uma mudança radical nesse quesito, quando da passagem de uma vila para cidade, o título de cidade trazia consigo uma importância simbólica para os súditos do território agraciado pelo rei. Os foros e prerrogativas de cidade implicavam em um tipo de diferenciação na escala imperial, sobretudo para determinados grupos sociais ligados à administração (funcionários régios civis e religiosos, e as autoridades locais).

Cláudia D. Fonseca, ao analisar as razões apresentadas pelas autoridades locais de Minas Gerais, quando dos pedidos de elevação dos arraiais em vila e das vilas em cidade, argumentou que existiam alguns "paralelismos" entre as "hierarquias urbanas e a estrutura social do Antigo Regime":

os termos vila e cidade, que classificam e hierarquizam as povoações no mundo português, fazem parte de um sistema de concessão de títulos, privilégios e funções (administrativas, religiosas, militares) que "ilustram" e "enobrecem" as localidades que os recebem; assim, as aglomerações urbanas são de certa forma personificadas, e podem ser assimiladas à nobreza que elas por vezes acolhem..$^{10}$

Nesse sentido, ser cidade significava ascender na hierarquia urbana de um conjunto de vilas de um dado território, mas, ao mesmo tempo, representava uma promoção na hierarquia social do Império Português. Atento a isso, no ano de 1800, Francisco Guedes de Carvalho e Meneses da Costa, governador da Capitania de Moçambique e Rios de Sena, localizada na África Oriental, enviou uma carta para o reino, solicitando a elevação da vila de Moçambique à categoria de cidade. Sobre essa matéria também se manifestaram os integrantes da câmara municipal de Moçambique e o administrador eclesiástico, em ofícios separados.

Para além dos seus papéis de centros administrativos e de instrumento de controle das populações e dos territórios, a produção de conhecimento

\footnotetext{
${ }^{8}$ BUENO, Beatriz Piccolotto Siqueira. "Dilatação dos confins: caminhos, vilas e cidades na formação da Capitania de São Paulo (1532-1822)” In Anais do Museu Paulista. 2009, vol.17, n. 2, p. 251-294, p. 292.

${ }^{9} \mathrm{Ibidem}, \mathrm{p} .252$.

${ }^{10}$ FONSECA, Cláudia Damasceno. "Funções, hierarquias e privilégios urbanos - A concessão dos títulos de vila e cidade na Capitania de Minas Gerais" In Varia História. 2003, 29, p. 39-51, p. 43.
} 
sobre as vilas, cidades, e aqui também poderíamos acrescentar a rede eclesiástica (composta por capelas e freguesias), nos permite adentrar aos pormenores do que formava o Império Português, possibilitando enxergar questões comuns, como as administrativas, por exemplo, ou as especificidades culturais, econômicas, sociais, entre outras.

Com o propósito de desenvolver uma reflexão com uma perspectiva que envolva diferentes escalas de observação, o objetivo deste artigo foi buscar a compreensão dos argumentos apresentados nas solicitações encaminhadas para Lisboa, pedindo a elevação da vila de Moçambique em cidade. A partir da caracterização dos elementos contidos nas cartas do governador-geral, dos vereadores da câmara municipal de Moçambique e do administrador eclesiástico, examinamos a forma como essas solicitações foram redigidas no ano de 1800, com particular atenção para as razões elencadas pelos diferentes autores.

Paralelamente, o estudo dessa documentação administrativa possibilita delinear algumas representações ${ }^{11}$ do território em foco. Por um lado, os argumentos fornecidos pelos autores das cartas contêm elementos de determinadas representações do que, em finais do século XVIII, conformava o que deveria ser uma cidade. Por outro, embora a correspondência analisada tivesse um objetivo em comum, ou seja, passar a imagem de que a vila de Moçambique tinha condições de "alcançar a graça" de receber o título de cidade, ela também apresentou as visões de mundo dos diferentes grupos envolvidos neste processo (nas figuras do governador-geral, dos vereadores da câmara e do religioso), todos com diferentes experiências e expectativas. Assim, almejamos contribuir com o debate que tem o Império Português como campo de problematização, possibilitando o diálogo com estudos que investigaram outras vilas/cidades dos territórios ultramarinos de finais do século XVIII e início do seguinte.

\section{Os argumentos do governador-geral}

Mas como essa história inicia?

Em 25 de Julho de 1800, Francisco Guedes de Carvalho Meneses da Costa $^{12}$, governador-geral da Capitania de Moçambique e Rios de Sena, es-

\footnotetext{
${ }^{11}$ Conforme Roger Chartier, a noção de representação permite "identificar o modo como em diferentes lugares e momentos uma determinada realidade social é construída, pensada, dada a ler". CHARTIER, Roger. A História Cultural: Entre Práticas e Representações. Rio de Janeiro, Bertrand, 1990, p. 17.

${ }^{12}$ Francisco Guedes de Carvalho Meneses da Costa foi governador-geral da capitania de Moçambique e Rios de Sena entre 27 de Agosto de 1797 e 10 de Setembro de 1801.
} 
creveu para D. Rodrigo de Sousa Coutinho, na época o secretário de Estado dos Negócios da Marinha e dos Domínios Ultramarinos, para que fosse encaminhado ao Príncipe Regente D. João um pedido de elevação da vila de Moçambique à categoria de cidade. ${ }^{13}$

O documento foi redigido em um momento político estratégico, como bem destacou o governador, referindo-se à "faustíssima ocasião em que Sua Alteza Real entra na regência de Seus Reinos e Domínios”, que havia ocorrido no ano passado. ${ }^{14}$ Pensando nas possíveis transformações que a nova situação administrativa do Império Português experimentaria, com o início da regência do Príncipe D. João, Meneses da Costa foi astuto na escolha das palavras e dos argumentos para elaborar o seu texto. Já no primeiro parágrafo, ele deixa claro a quem desejava sensibilizar para obter a "graça de Sua Alteza Real, tão útil aos seus Fiéis Vassalos nestas colônias". Depois disso, procurou persuadir o Príncipe Regente argumentando que seria importante "querer aumentar a sua tão Antiga e Poderosa Monarquia com mais o número de uma Cidade". ${ }^{15}$ Assim, tal ato poderia significar engrandecimento e fortalecimento do Império Português.

Apesar de Azevedo argumentar que a concessão do título de cidade não seguia uma lógica específica de critérios ${ }^{16}$, por vezes se considerou que as principais razões apontadas para a fundação de uma cidade eram a importância da população e das riquezas econômicas de uma dada localidade. Em finais do século XVIII, o governador-geral julgou que este era um caminho possível de ser trilhado. Na carta enviada à Lisboa, Meneses da Costa afirmou que a vila de Moçambique "excede a algumas cidades" de Portugal, conhecidas pessoalmente por ele, como Pinhel, Miranda do Douro e Penafiel. Além disso, tinha o atrativo de um "grande porto de mar" frequentado por "nações das quatro partes do mundo". No que se refere aos aspectos econômicos, ele mencionou que a riqueza do comércio provinha, sobretudo, de três mercadorias: escravos, ouro e marfim. Os escravos eram encaminhados para as Américas e os dois produtos seguintes conduzidos para a Ásia. Todavia, ao analisarmos o conjunto

\footnotetext{
${ }^{13}$ ARQUIVO HISTÓRICO ULTRAMARINO, Moçambique, cx. 85, doc. 43. Carta do Governador-geral de Moçambique e Rios de Sena, Francisco Guedes de Carvalho Meneses da Costa, para o D. Rodrigo de Sousa Coutinho, solicitando a elevação da vila de Moçambique à categoria de cidade, de 25 de Julho de 1800. [Doravante, utilizaremos a sigla AHU para identificar o Arquivo Histórico Ultramarino].

${ }^{14}$ D. João (1767-1826) foi nomeado Príncipe Regente no dia 13 de julho de 1799.

${ }^{15} \mathrm{AHU}$, Moçambique, cx. 85, doc. 43. Carta do Governador-geral de Moçambique e Rios de Sena, Francisco Guedes de Carvalho Meneses da Costa, para o D. Rodrigo de Sousa Coutinho, solicitando a elevação da vila de Moçambique à categoria de cidade, de 25 de Julho de 1800.
}

${ }^{16}$ AZEVEDO, op. cit., p. 23-78. 
da documentação administrativa da capitania de Moçambique e Rios de Sena, no qual a carta do governador-geral está inserida, nota-se a referência à um quadro econômico radicalmente contrário ao que foi formulado por Meneses da Costa. Para a segunda metade do século XVIII, abundavam queixas sobre o estado de ruína do território, embora alguns administradores ressaltassem a potencialidade intrínseca da região. ${ }^{17}$

Ainda sobre a questão econômica, o governador também informava que a população local de não-súditos, “os habitantes negros destes países com que confinamos", não representariam qualquer perigo para a vida financeira da capitania. Segundo ele, "jamais navegaram navios para nos poderem tirar a utilidade deste comércio", não estavam organizados em termos militares ("tropas de terra regulada") e não possuíam "artilharia" para fazer algum tipo de oposição às leis e aos estabelecimentos portugueses. O governador ainda acrescentava que estes africanos não recebiam qualquer "socorro" de outra nação estrangeira para enfrentarem a soberania lusa.

No tocante à população composta pelos súditos da Coroa, o governador-geral teceu alguns comentários, com o intuito de conduzir até o Príncipe Regente mais elementos que o auxiliasse na decisão de elevar a vila de Moçambique à categoria de cidade. Meneses da Costa informava a existência de "muitos casamentos entre as principais famílias" e o aumento do número de nascimentos. É interessante a atenção que ele dedicou à longevidade dos integrantes dessas famílias, tanto de europeus quando daquelas "naturais do país", de forma que existiam "muitos netos e bisnetos que conhecem seus avós e bisavós". A presença de três ou quatro gerações de uma mesma família, com idosos "em boa disposição" e por alguns deles não fazerem uso de "remédios da botica", causava admiração no governador. Todavia, ele destacou que a longevidade maior era entre as mulheres, que em alguns casos, alcançavam "mais de cem anos". Por vezes, elas também eram apontadas como as responsáveis pela manutenção do catolicismo na ilha de Moçambique, sendo algumas "bisavós da casta europeia" as encarregadas de apresentar seus descendentes à pia batismal. ${ }^{18}$

\footnotetext{
${ }^{17}$ Sobre alguns aspectos da vida administrativa da capitania de Moçambique e Rios de Sena, ver WAGNER, Ana Paula. População no Império Português: recenseamentos na África Oriental Portuguesa na segunda metade do século XVIII. Tese (Doutorado em História). Universidade Federal do Paraná, Curitiba, 2009.

${ }^{18} \mathrm{AHU}$, Moçambique, cx. 85, doc. 43. Carta do Governador-geral de Moçambique e Rios de Sena, Francisco Guedes de Carvalho Meneses da Costa, para o D. Rodrigo de Sousa Coutinho, solicitando a elevação da vila de Moçambique à categoria de cidade, de 25 de Julho de 1800. Para 1781, temos a descrição de um cenário oposto ao apresentado por Meneses da Costa. Em um ofício do governador interino da capitania de Moçambique e Rios de Sena encontramos referências sobre a "sensível falta de habitantes portugueses que se experimenta em todo aquele Estado", a "falta de religião que se experimenta nos nossos católicos" e, sobre o comércio, "não
} 
Ainda sobre a população que vivia na vila de Moçambique, o governador-geral fez uma breve descrição:

Há muitos filhos e filhas naturais do país e da costa europeia muito claros e de cabelos louros, e tão boa cor que parecem filhos de países Europeus do Norte. Tem muita viveza e talentos para tudo que deles se quisesse pretender; assim houvessem aqui meios de serem bem educados.

Como se nota, o governador-geral preocupou-se em mostrar para a Coroa a qualidade dos indivíduos que compunham a população da futura cidade, valorizando aspectos como o tipo físico com padrões europeus, a longevidade dos habitantes e a relação destes indivíduos com uma espécie de continuidade de valores europeus (com manutenção de costumes, modo de vida, religião católica etc.). ${ }^{19}$

Em determinado ponto da apresentação dos motivos que justificariam a elevação da vila de Moçambique à categoria de cidade, o governador-geral se deteve em escrever sobre o clima, a salubridade da vila e a saúde da população. A África Oriental tinha, na sua visão, um clima sadio como o da Europa. Embora determinados habitantes "padecessem de algumas moléstias", elas não eram decorrentes da má qualidade do clima, mas, segundo ele, devido ao comportamento destes indivíduos. Para Meneses da Costa, aqueles com "gênio extravagante", como os degredados, eram os que, "pela sua má conduta", logo adoeciam..$^{20}$

Para se compreender o raciocínio construído pelo governador-geral é preciso entender que, em finais do século XVIII, para as concepções médicas em voga, ligadas às ideias neo-hipocráticas ${ }^{21}$, os fatores ambientais assumiam

havia dúvida que se estava arruinado" e ficaria "arruinado cada vez mais" se providências não fossem tomadas (AHU, Moçambique, cx. 38, doc. 24. Consulta do Conselho Ultramarino, de 25 de fevereiro de 1781).

${ }^{19} \mathrm{Em}$ outra circunstância o próprio governador-geral não teve um olhar tão animador sobre as qualidades e as características dos vassalos portugueses instalados na África Oriental. Cerca de 1799, Meneses da Costa escreveu: "deve também trazer-se à memória que esta Capitania é composta de diversas qualidades de gentes, como são europeus, e muitos destes degredados de péssimos costumes, que a nossa Religião, mesmo ali não pode conservar um bom pé pelo ajuntamento e comunicação de tantas outras diversas [...]. AHU, Moçambique, cx. 84, doc. 87. Carta do governador-geral da capitania de Moçambique e Rios de Sena, Francisco Guedes de Carvalho e Meneses da Costa para o Príncipe Regente, s/d [posterior a Julho de 1799].

${ }^{20} \mathrm{AHU}$, Moçambique, cx. 85, doc. 43. Carta do Governador-geral de Moçambique e Rios de Sena, Francisco Guedes de Carvalho Meneses da Costa, para o D. Rodrigo de Sousa Coutinho, solicitando a elevação da vila de Moçambique à categoria de cidade, de 25 de Julho de 1800.

${ }^{21}$ Conforme Denise Diniz, "[...] a medicina hipocrática entendia estar o ser humano submetido a certas regras prescritas pela natureza [...]", conhecer estas regras era essencial "[...] para viver corretamente, no estado de saúde". Da mesma forma, "[...] as enfermidades não eram consideradas isoladamente: o homem vítima da doença era visto com toda a natureza que o circunda. Existiriam leis gerais que regem a natureza em todas as suas qualidades individuais". DINIZ, Denise Scofano. A "ciência das doenças" e a "arte de curar": 
uma grande importância na explicação das doenças e da saúde da população, sobretudo em locais de clima quente. Relacionava-se as condições ambientais (naturais e sociais) com o estado de salubridade ou de insalubridade dos lugares. Ainda que não fosse um médico, ou um físico-mor, provavelmente estes conhecimentos faziam parte do universo mental de Meneses da Costa e nos ajudam a compreender porque ele destacou estes aspectos para sensibilizar o Príncipe Regente.

O governador-geral escreveu que a salubridade da ilha de Moçambique havia sido conquistada em razão de alguns fatores, que envolviam elementos de ordem material e comportamental. o primeiro deles era que a construção de novos edifícios foi realizada segundo "conhecimentos físicos", destacando o uso de vidraças que auxiliavam na conservação da "pureza do ar vital". A boa qualidade da água foi igualmente sublinhada, a partir do aumento do número de cisternas. Em relação aos hábitos da população, foi mencionado o consumo de determinadas bebidas. Trocou-se a ingestão de bebidas alcóolicas "fortes extraídas de grãos e palmeiras" ${ }^{22}$ produzidas em Moçambique, além de "aguardentes e cachaças", pelo uso de chá e café. Meneses da Costa viu essa substituição como positiva, em função dos efeitos terapêuticos destas últimas. O aumento da transpiração, proporcionado por esses líquidos, era tido pelo governador como proveitoso para "repelir o veneno" que poderia entrar pelo corpo da população. ${ }^{23}$ Embora as propriedades medicinais do chá e do café fossem mais complexas do que o raciocínio apresentado pelo governador, não deixa de ser importante a menção de que as bebidas alcoólicas, associadas com um tipo de comportamento não morigerado, foram substituídas por outras tidas por mais inofensivas.

Além disso, Meneses da Costa preocupou-se em desconstruir uma certa imagem de "mau clima" que também era elaborada por aqueles indivíduos

trajetórias da medicina hipocrática. Dissertação (Mestrado em Ciências Humanas e Saúde). Universidade do Estado do Rio de Janeiro, Rio de Janeiro, 2006, p. 27.

${ }^{22}$ Um exemplo destas bebidas alcoólicas fabricada localmente era a sura, produzida a partir da fermentação da seiva de várias espécies de palmeira. Ver WAGNER, op. cit., p. 83.

${ }^{23}$ Nesse aspecto, Meneses da Costa apresenta argumentos do que poderíamos chamar de um senso comum da época. Luís Vicente de Simoni, um médico italiano que atuou como físico-mor em Moçambique entre os anos de 1819 e 1821, ao escrever o Tratado Medico sobre Clima enfermidades de Moçambique (1821), entre vários assuntos, discutiu um pouco sobre o consumo de determinados tipos de bebidas na capitania. Simoni indicava que o chá e o café eram produtos ingeridos na ilha. Todavia, apresentou cautela quanto às propriedades terapêuticas destes. No Tratado Médico ele descreveu, de acordo com os seus conhecimentos, algumas vantagens e prejuízos que a ingestão destas bebidas causava no organismo dos indivíduos que viviam na África Oriental. SIMONI, Luís Vicente de (1821). Tratado Médico sobre Clima e Enfermidades de Moçambique. Biblioteca Nacional do Rio de Janeiro, Sessão de Manuscritos, 1821, cód. I-47,23,17. 
que se dirigiam para a Moçambique, como militares e agentes régios (civis e religiosos), e que estrategicamente alegavam o "padecimento de muitas moléstias", tanto para fugirem das suas obrigações, quanto como elemento de barganha para obtenção de algum tipo de recompensa pelos esforços realizados em nome da Coroa. ${ }^{24}$

Interessado naqueles indivíduos que escolhiam deliberadamente ficar na capitania, sobretudo constituindo casamentos, o governador escreveu não consentir "que se fale mal do país, nem tão pouco que se perturbe ou aconselhe mal" estes homens. Ou seja, a imagem de um território insalubre e doentio não era um bom atrativo para que novos súditos se dirigissem e se fixassem na capitania. Ao contrário, ela desencorajaria aqueles indivíduos de fazê-lo. Em vista do disso, a possibilidade de aumento do número de habitantes ficaria mais restrita. Esta era uma questão preocupante para o governador-geral de Moçambique e Rios de Sena, assim como para os demais administradores portugueses, na medida em que havia o entendimento de que a população de um território era um importante instrumento de riqueza do Estado. ${ }^{25} \mathrm{Com}$ o propósito de estar em conformidade com os princípios norteadores empregados no gerenciamento do Império Português, Meneses da Costa mostrou que estava empenhado no aumento do número de súditos, sobretudo por considerar que aquele era um elemento importante no processo que justificaria a elevação da vila de Moçambique à categoria de cidade.

Em síntese, através das informações mencionadas na carta redigida pelo governador-geral, como as questões econômicas, a relevância da população (tanto pela sua qualidade quanto pela quantidade dos habitantes), a salubridade do território e o impacto positivo na saúde dos súditos, foi construída uma imagem da vila de Moçambique, desejosa de passar a ideia de que estaria ela apta para receber o título de cidade. Da mesma forma, percebe-se, na análise da carta de Meneses da Costa, os elementos que ele considerava importante nesse processo de sensibilização do Príncipe Regente. Ou seja, por trás da

\footnotetext{
${ }^{24}$ Por vezes, a obediência e o bom desempenho dos funcionários régios na realização das suas tarefas são interpretados pela historiografia como uma moeda de troca, utilizada na negociação de outros cargos na administração do Império Português e no recebimento de mercês. Assim, a valorização de dificuldades enfrentadas pelos indivíduos no exercício das suas funções, sobretudo em territórios ultramarinos, poderia interferir na qualidade destas recompensas. Por esta razão, não seria fora de propósito encontrarmos entre a documentação administrativa manifestações de alguns indivíduos que, quando de suas passagens por Moçambique, buscaram evidenciar junto às autoridades metropolitanas as suas capacidades de superação ao clima e as "moléstias" existente naquele território. Sobre uma "economia de mercê", ver OLIVAL, Fernanda. As Ordens Militares e o Estado Moderno: honra, mercê e venalidade em Portugal (1641-1789). Lisboa, Estar, 2001.

${ }^{25}$ Sobre a importância atribuída à população no interior da política portuguesa de meados do século XVIII, ver WAGNER, op. cit.
} 
valorização de certos aspectos do território, dissertados no documento, podemos enxergar determinadas representações de cidade.

\section{Os membros da câmara municipal e o administrador eclesiástico também se pronunciaram}

Como referido anteriormente, sobre o pedido de atribuição do estatuto de cidade, o governador-geral também convocou os membros da câmara municipal da vila de Moçambique a se manifestarem sobre essa demanda: "mandei que o Senado da Câmara desta mesma Vila me informasse e declarasse algumas circunstâncias, que lhe ocorressem, tendentes ao fim a que me propunha de procurar alcançar esta Graça de Sua Alteza Real tão útil aos seus Fiéis Vassalos nestas colônias". ${ }^{26} \mathrm{Em}$ função deste pedido, em anexo à carta de Meneses da Costa, encontra-se aquela redigida pelos integrantes da câmara, com data de 23 de Julho de $1800 .{ }^{27}$

O protocolo inicial do documento tem semelhanças com aquele feito pelo governador-geral. Enfatizou-se o impacto positivo que a ação de "Sua Alteza Real" traria aos seus "fiéis e felizes vassalos", de participarem dos benefícios temporal e espiritual quando da elevação da vila de Moçambique ao estatuto de cidade. Entretanto, diferentemente da carta de Meneses da Costa, o documento assinado pelo juiz ordinário José António de Araujo e Lima, pelos vereadores José Antonio Caldas, José Pereira Machado e Manoel Joaquim Pereira Chaves, e pelo procurador Domingos Bento Guerreiro, na respectiva ordem, recuperou alguns elementos da história da vila e da capitania como um todo, ressaltando a existência de uma infraestrutura político-administrativa consolidada.

Os membros da câmara começaram por dar informações muito básicas, como a referência de que a vila de Moçambique integrava a capitania de Moçambique e Rios de Sena, e era a "capital de toda a Costa da África Oriental Portuguesa”. Por esta razão, "há muitos anos”, aquele território contava com a figura de um governador e capitão general. ${ }^{28}$ Também indicaram a existência

\footnotetext{
${ }^{26} \mathrm{AHU}$, Moçambique, cx. 85, doc. 43. Carta do Governador-geral de Moçambique e Rios de Sena, Francisco Guedes de Carvalho Meneses da Costa, para o D. Rodrigo de Sousa Coutinho, solicitando a elevação da vila de Moçambique à categoria de cidade, de 25 de Julho de 1800.

${ }^{27} \mathrm{AHU}$, Moçambique, cx. 85, doc. 43. Anexo - Carta do Senado da Câmara da vila de Moçambique para o Governadorgeral de Moçambique e Rios de Sena, Francisco Guedes de Carvalho Meneses da Costa, com argumentos para a elevação da vila de Moçambique à categoria de cidade, de 23 de Julho de 1800.

${ }^{28} \mathrm{Um}$ decreto de 1752 separou a capitania de Moçambique e Rios de Sena do governo do Estado da Índia, constituindo uma capitania independente. Após essa decisão da Coroa, a ilha de Moçambique e as terras firmes situadas defronte a ela, assim como as feitorias de Inhambane, Sofala, Cabo Delgado e os Rios de
} 
de mais oito vilas, distribuídas ao longo da capitania: Quelimane, Sena, Tete (onde residia o governador subordinado de Rios de Sena), Zumbo, Manica, Sofala, Inhambane e Ibo (nas Ilhas do Cabo Delgado). ${ }^{29}$

Mas por que razão os autores da carta retomaram estes dados em particular? Possivelmente almejaram destacar a importância da vila de Moçambique frente aos demais espaços que integravam a capitania, sobretudo pela presença de um funcionário régio em especial. Um governador-geral, assim como vice-reis, constituíam um elemento chave no gerenciamento do grande número de territórios que conformavam o Império Português, estruturado numa complexa hierarquia de cargos e órgãos. Tidos como representantes do rei português nas conquistas, os governadores tinham atribuições concomitantemente políticas e militares ${ }^{30}$, sendo caracterizados como funcionário de confiança da Coroa.

Nesse sentido, podemos considerar que a menção de que a vila de Moçambique "já há muitos anos [tem] a honra de ter um Senhor Governador e Capitão General" ${ }^{31}$ foi uma questão estrategicamente elaborada pelos membros da câmara e informada no texto para mostrar a relevância daquela vila e do seu posicionamento favorável na complexa engrenagem administrativa do Império Português. Da mesma maneira, a referência ao conjunto de vilas existentes na capitania, e por consequência ao aparato institucional das

Sena seriam administradas por um governador-geral, com o título de capitão-general, cuja residência continuaria sendo na ilha. As terras dos Rios de Sena, composta por Quelimane, Tete, Sena, Manica e Zumbo, além das minas e outras feiras, ficariam sob a responsabilidade de um tenente-general, subordinado ao governador-geral de Moçambique. Refira-se que antes de 1752, a distribuição dos comandos administrativos era bem parecida, pelo menos desde 1709 havia a nomeação regular do cargo de governador dos Rios de Sena, do mesmo modo subordinado ao governador-geral de Moçambique. Todavia, a mudança significativa foi que ambos os governadores não estariam mais dependentes do governo do Estado da Índia. (WAGNER, op. cit., p. 88-89).

\footnotetext{
${ }^{29}$ Embora a presença portuguesa na África Oriental já se fizesse sentir desde o século XVI, e mais intensamente no século seguinte, o estabelecimento de vilas e câmaras só ocorreu a partir da década de 1760 , e ainda assim não cobriram todo aquele território. De acordo com a Instrução de Governo remetida para a capitania de Moçambique e Rios de Sena em 1761, deviam ser criadas vilas e câmaras nas seguintes localidades: ilha de Moçambique, Quelimane, Sena, Tete, Zumbo, Manica, Sofala, Inhambane e Ilhas de Querimba. Ver AHU, Moçambique, cx. cx. 19, doc. 63-A. Cópia da Instrução dada a Calisto Rangel Pereira de Sá, que vai por governador e capitão general da Praça de Moçambique, Rios de Sena e Sofala, de 7 de maio de 1761.

${ }^{30}$ Conforme Wagner, "sob a jurisdição do governador-geral encontravam-se outras autoridades, como os governadores subalternos ou, às vezes, indivíduos com títulos de capitães e sargentos que eram encarregados de distritos menores ou de fortalezas. Era competência dos governadores, em caráter provisório, a nomeação de alguns postos militares e de empregos civis e eclesiásticos, até que novas ordens do reino fossem enviadas" (WAGNER, op. cit., p. 42-43).

${ }^{31} \mathrm{AHU}$, Moçambique, cx. 85, doc. 43. Anexo - Carta do Senado da Câmara da vila de Moçambique para o Governadorgeral de Moçambique e Rios de Sena, Francisco Guedes de Carvalho Meneses da Costa, com argumentos para a elevação da vila de Moçambique à categoria de cidade, de 23 de Julho de 1800.
} 
respectivas câmaras municipais existentes na África Oriental Portuguesa, pode ser interpretada como um recurso utilizado pelos membros da câmara para mostrar o quanto o Estado Português se fazia presente naquele território. A materialização da autoridade lusa, tanto por meio da figura do governador-geral como dos oficiais da câmara (administração local), significava o enquadramento político-administrativo do território, das riquezas e dos habitantes. Ou seja, o juiz, os vereadores e o procurador da câmara estavam construindo argumentos e um quadro de condições, entendidas por eles como favoráveis, com o intuito de sensibilizar o Príncipe Regente para a obtenção do título de cidade. $^{32}$

Um outro ponto mencionado na carta, dizia respeito aos elementos integrantes do traçado urbano e do plano arquitetônico da vila de Moçambique. Nesse aspecto é interessante a divergência de opiniões da carta escrita pelo governador-geral e aquela redigida pelos membros da câmara. Meneses da Costa apresentou uma visão mais pessimista e objetiva sobre o assunto, escrevendo sobre uma "falta de notória grandeza, assim nos edifícios públicos e particulares" e sobre a ausência de "boas ruas" na vila. Para ele, talvez isso pudesse ser visto como um "obstáculo". ${ }^{33}$

Os integrantes da câmara descreveram um outro cenário, mais detalhado e próspero. Entre os edifícios, eles destacaram a existência de uma "boa alfândega", uma excelente "casa da câmara com cadeia", "um decente palácio para os governadores", "uma muito suficiente Sé”, "uma boa Misericórdia" e "outras igrejas asseadas". Sobre as casas dos moradores, informaram serem estas "fabricadas e ornadas com nobreza e a imitação das da Europa". Nesta carta também existia uma breve referência à salubridade da vila, e o consequente "beneficiamento" que isso trazia para a saúde da população. Os membros da câmara atribuíam parte da responsabilidade deste bom estado da vila, "mais asseada e melhor arrumada", às ações encaminhadas pelo então governador-geral. Eles concluem este grupo de questões informando que, em razão do "desvelo" de Meneses da Costa, a vila encontrava-se "cada vez mais aumentada em população", "mais luzida no tratamento dos seus cidadãos", "mais povoada e cheia de casas".

\footnotetext{
${ }^{32}$ Todavia, a existência de uma vila ou povoado não caracterizava uma pré-condição, uma espécie de estágio anterior, para a ereção de uma cidade. Esta poderia ser criada sem nunca ter havido uma vila anteriormente. Na América Portuguesa, temos os exemplos das cidades de Salvador da Bahia de Todos os Santos (fundada em 1549) e de São Sebastião do Rio de Janeiro (criada em 1565). Ver AZEVEDO, op. cit., p. 29.

${ }^{33} \mathrm{AHU}$, Moçambique, cx. 85, doc. 43. Carta do Governador-geral de Moçambique e Rios de Sena, Francisco Guedes de Carvalho Meneses da Costa, para o D. Rodrigo de Sousa Coutinho, solicitando a elevação da vila de Moçambique à categoria de cidade, de 25 de Julho de 1800.
} 
Não só neste ponto da carta, mas ao longo dela, podemos perceber parte dos mecanismos que articulavam as engrenagens do Império Português. Como já dito, os membros da câmara foram convocados a se manifestarem sobre a questão da criação da cidade. Eles não estavam escrevendo diretamente para o reino, embora lhes fosse autorizado fazê-lo. A correspondência estava endereçada ao governador-geral. $\mathrm{Na}$ análise desta carta e daquela escrita pelo governador, podemos perceber o uso de um artifício retórico, dos recursos da adulação para atingir determinados objetivos. Os membros da câmara não pouparam elogios, exaltando as qualidades do governador ${ }^{34}$. Era a figura que Meneses da Costa representava que necessitava ser tocada, para que o pedido da obtenção da "graça" de criação da cidade fosse encaminhado para o reino. A súplica saída da África Oriental certamente teria mais peso se compartilhada pelas diferentes instâncias administrativas (o governador-geral, os membros da câmara e o administrador episcopal).

Aliás, aquela não foi a primeira vez que a Coroa recebeu um pedido desta natureza. Em agosto de 1783, o ouvidor-geral de Moçambique, António José de Morais Durão, escreveu uma carta muito sucinta para o reino solicitando para aquela vila a mercê de sua elevação a cidade..$^{35}$ Até onde temos conhecimento, tratou-se de uma ação isolada do ouvidor e não resultou em qualquer desdobramento. Passados quase 17 anos, orquestrava-se uma nova tentativa, dessa vez envolvendo distintos grupos.

Nesse processo de pedido de elevação da vila de Moçambique ao estatuto de cidade, também devemos referenciar a carta de Fr. Amaro José de Santo Thomaz, religioso dominicano que ostentava o título de Bispo de Pentacomia ${ }^{36}$.

\footnotetext{
${ }^{34}$ Destacamos a frase: "pelo eficaz zelo de V.Exa. que tanto se interessa em beneficiar e exaltar esta Colônia, que tem a felicidade de ser V.Exa. seu tão benemérito Governador e Capitão General.” AHU, Moçambique, cx. 85, doc. 43. Anexo - Carta do Senado da Câmara da vila de Moçambique para o Governador-geral de Moçambique e Rios de Sena, Francisco Guedes de Carvalho Meneses da Costa, com argumentos para a elevação da vila de Moçambique à categoria de cidade, de 23 de Julho de 1800.

${ }^{35} \mathrm{AHU}$, Moçambique, cx. 43, doc. 25. Carta do Ouvidor-geral de Moçambique, António José de Morais Durão, solicitando a elevação da vila de Moçambique à categoria de cidade, de 15 de Agosto de 1783. Esse ouvidor esteve na América Portuguesa, na capitania do Piauí, em 1772. Na ocasião, elaborou um relatório bastante pessimista sobre a cidade de Oeiras, que havia sido instalada dez anos antes (o rei D. José I concedeu o título de cidade à antiga vila de Mocha, alterando-lhe o nome). Quer dizer, António Durão detinha elementos para julgar as condições de Moçambique, por contraste às povoações que conheceu no Piauí. Ver "Descrição da capitania de São José do Piauí, pelo ouvidor-geral António José de Morais Durão, de 15 de junho de 1772" In MOTT, Luiz. “Descrição da capitania de São José do Piauí, 1772” In Revista de História, São Paulo, 1977, 112, p. 552-566. ${ }^{36}$ João Francisco Marques, em um estudo sobre o frei em questão, explica que "a rainha D. Maria I, no uso das prerrogativas do direito do Padroado, apresentou à Santa Sé, em 25 de Agosto de 1782, para bispo desta prelazia nullius a Fr. Amaro José de Santo Thomaz, então de trinta e sete anos, que Pio VI confirmou pela bula Apostolatus officium meritis, de 19 de Julho de 1783, com o título de Pentacómia in partibus infidelium, o que lhe permitia exercer todos os actos sacramentais próprios da ordem episcopal no território de
} 
Presente na África Oriental Portuguesa desde o início da década de 1780, ele procurou fortalecer a solicitação encaminhada pelo governador-geral e pelos membros da câmara, destacando aspectos sobre a relevância daquela vila constituir uma sede de bispado.

A carta do Bispo de Pentacomia, datada de 23 de Julho de 1800, estava endereçada diretamente para D. Rodrigo de Sousa Coutinho. ${ }^{37}$ Até onde pudemos perceber, esse documento foi lido pelo governador-geral e alguns trechos dele foram adaptados por Meneses da Costa. Entretanto, enquanto este tinha em foco os benefícios temporais e espirituais, o religioso apenas esteve interessado em ressaltar o quanto a ação do Príncipe Regente resultaria em fortalecimento da presença católica na África Oriental Portuguesa.

O Fr. Amaro José de Santo Thomaz iniciou seu texto declarando que, "unindo-me aos desejos deste povo", tomava a "liberdade de expor a Sua Alteza" o quanto seria "útil e conveniente" transformar a prelazia de Moçambique em bispado, o que só poderia ocorrer com a elevação da vila ao estatuto de cidade. Ele retomou a bula papal de Paulo V, com data de 1612, a qual separava a área territorial compreendida entre o Cabo de Guardafui e o da Boa Esperança do Arcebispado de Goa ${ }^{38}$. A partir de então o administrador eclesiástico de Moçambique adquiria um pouco mais de autonomia para tomar uma série de resoluções, "tinha o direito de usar vestes prelatícias, nomear e destituir párocos, fazer a visita pastoral das igrejas, informar Lisboa do estado das missões, apontando deficiências e soluções". ${ }^{39}$ Acrescente-se que com a concessão do título de "Bispo de Pentaconia" no ano de 1783, em caráter "in partibus infidelium" 40, houve a ampliação dos poderes de Fr. Amaro José de Santo Thomaz. Desde aquela data, lhe fora autorizado exercer tarefas

que já era responsável quanto ao governo eclesiástico. Continuava este, todavia, ligado canonicamente à arquidiocese de Goa como se fosse um bispado sufragâneo" (MARQUES, João Francisco. "O Dominicano bracarense D. Fr. Amaro José de Santo Thomaz, primeiro bispo residente de Moçambique” In Estudos em homenagem ao Professor Doutor José Marques, vol. 1. Porto, Faculdade de Letras da Universidade do Porto, 2006, p. 331-358, p. 343-344).

${ }^{37}$ AHU, Moçambique, cx. 85, doc. 42. Carta do Bispo de Pentacomia, Fr. Amaro José de Santo Thomaz, para D. Rodrigo de Sousa Coutinho, solicitando que o território seja elevado a Bispado, de 23 de Julho de 1800. Esta carta não se encontrava anexada à correspondência do governador-geral e dos membros da câmara. Ela constituía um documento separado.

${ }^{38}$ Segundo Marques, “toda a África Oriental sob domínio português” pertencia “à diocese de Goa, criada em 1563. O primeiro desmembramento administrativo-eclesiástico foi em 1612. Em 1783, se daria um desmembramento de ordem espiritual, com a nomeação de um bispo residente para a prelazia de Moçambique" (MARQUES, op. cit., p. 338).

${ }^{39}$ Ibidem, p. 338.

${ }^{40}$ Trata-se de uma expressão em latim, com um significado geral de "nas terras dos infiéis". O termo "in partibus” era empregado para designar um bispo sem sede. Entretanto, constituía apenas título honorífico. 
pertencentes à dignidade episcopal. Ele pôde "consagrar os Santos Óleos", o que era tomado como uma das maiores prerrogativas do sacerdócio de um bispo. Essa ação foi considerada um ganho importante para a população católica da capitania. Por vezes, segundo o religioso, em razão dos navios saídos de Goa não arribarem na África Oriental, ficava-se sem esse importante elemento da liturgia da igreja. ${ }^{41}$

O Bispo de Pentacomia também escreveu que de todos os párocos existentes na capitania, apenas três deles não foram ordenados (tornados sacerdotes) pelas suas mãos. Na ótica do religioso, a não dependência do arcebispado de Goa para a ordenação e a instrução dos "filhos da terra" representava uma economia nas despesas das famílias locais, constituindo um benefício para parte da população. Do mesmo modo, significava maiores chances daqueles indivíduos não se "perderem", por "estarem tão distantes dos seus pais" em outro território.

Porém, essas prerrogativas citadas anteriormente, consagrar os Santos óleos e ordenar novos religiosos, estavam ligadas diretamente à pessoa do Fr. Amaro José de Santo Thomaz, em razão do título por ele recebido, de Bispo de Pentacomia. Ou seja, era um título privativo dele. Aquela não era uma qualificação de qualquer religioso que assumisse o comando da Administração Eclesiástica de Moçambique. Não existiam garantias de que, no futuro, um novo administrador viesse a receber o mesmo título. E aí residia o ponto de argumentação do dominicano. Segundo ele, esses benefícios seriam mais "permanentes e decorosos" se a prelazia fosse elevada à bispado.

De maneira semelhante aos autores das outras cartas, o Bispo de Pentacomia entrou no jogo de exaltação do território, de construção de uma imagem positiva. De maneira breve ele escreveu que a capitania experimentava o aumento da população e de novos edifícios, resultando assim em "maior esplendor, civilidade e luzimento". Ele argumentou que essas características colocavam a vila de Moçambique em uma posição superior, em relação à “outras povoações do Ultramar que gozam há muito tempo das prerrogativas de cidade e de Bispo Diocesano". 42

Sobre os aspectos de ordem prática, do processo de criação do Bispado, o religioso comentou que a inexistência de um cabido na vila de Moçambique, não era um empecilho. Porque, segundo o frei, muitos bispados do ultramar

\footnotetext{
${ }^{41}$ AHU, Moçambique, cx. 85, doc. 42. Carta do Bispo de Pentacomia, Fr. Amaro José de Santo Thomaz, para D. Rodrigo de Sousa Coutinho, solicitando que o território seja elevado a Bispado, de 23 de Julho de 1800.

${ }^{42}$ AHU, Moçambique, cx. 85, doc. 42. Carta do Bispo de Pentacomia, Fr. Amaro José de Santo Thomaz, para D. Rodrigo de Sousa Coutinho, solicitando que o território seja elevado a Bispado, de 23 de Julho de 1800.
} 
não o tinham. Em relação à côngrua do bispo, não haveria problema que este recebesse o mesmo montante que até então era dado ao Bispo de Pentacomia. No tocante a esses pormenores, foi possível perceber que o governador-geral tomou conhecimento do conteúdo da carta do religioso, também mencionando esses dois pontos no seu texto. Porém, Meneses da Costa informou qual era o valor que o Bispo de Pentacomia recebia de côngrua ("três mil cruzados") e que aquele era um salário com que o futuro bispo poderia se sustentar "com decência". 43

É interessante notar que o Bispo de Pentacomia investiu pouco na construção de argumentos de que criação do bispado traria algum tipo de benefício para o fortalecimento da presença da igreja católica na região. Em um momento específico da carta, em que o religioso mencionava a grande extensão do território, ele escreveu que ali existiam muitas "terras incultas e cheias de cafrarias de vida brutal". ${ }^{44}$ Aquela foi a única circunstância que o religioso esboçou preocupação com um grupo da população que não vivia segundo os parâmetros católicos e europeus.

O motivo da nossa estranheza é que, em outro momento, como a já referida carta do ouvidor-geral de 1783, em que ele também solicitava a elevação da vila de Moçambique à categoria de cidade, notamos uma maior ênfase nesse tema do comportamento da população. António José de Morais Durão escreveu que tentava evitar determinados "pecados públicos" praticados pelos habitantes, como "furtos" e "concubinatos". Ele argumentou que a tarefa lhe exigia "muito trabalho e constância", "porque os costumes muito inveterados são difíceis de desarreigar". Ao que parece, o alvo dos seus comentários era uma determinada parcela da população, composta pelos africanos não-católicos: "principalmente em um povo como este, composto de muitas nações pela maior parte bárbaros, que se pervertem umas com as outras, reduzindo tudo a uma torpe libertinagem". ${ }^{45}$ A argumentação do ouvidor-geral foi construída tendo por base a ideia de que a mercê do estatuto de cidade à vila de Moçambique e a criação de bispado auxiliariam nos esforços empreendidos para a moralização das condutas dos habitantes.

\footnotetext{
${ }^{43} \mathrm{AHU}$, Moçambique, cx. 85, doc. 43. Carta do Governador-geral de Moçambique e Rios de Sena, Francisco Guedes de Carvalho Meneses da Costa, para o D. Rodrigo de Sousa Coutinho, solicitando a elevação da vila de Moçambique à categoria de cidade, de 25 de Julho de 1800.

${ }^{44}$ Ao longo do século XVIII, o termo "cafre" apareceu na documentação administrativa portuguesa para fazer referência aos africanos nascidos na costa oriental. Embora a expressão fosse utilizada pelos árabes para designar o africano não islamizado da costa africana oriental, com o passar do tempo os portugueses empregaram-na para se reportarem aos africanos em geral, independentemente da religião. Ver WAGNER, op. cit.

${ }^{45}$ AHU, Moçambique, cx. 43, doc. 25. Carta do Ouvidor-geral de Moçambique, António José de Morais Durão, solicitando a elevação da vila de Moçambique à categoria de cidade, de 15 de Agosto de 1783.
} 


\section{E como essa história teria terminado?}

O esforço orquestrado por todos esses indivíduos inseridos em diferentes segmentos da hierarquia do Império Português, não obteve o êxito desejado. Ao menos, imediato. A elevação da vila de Moçambique à categoria de cidade ocorreu quase duas décadas mais tarde, em setembro de $1818 .^{46}$ Entretanto, tomando a correspondência referida neste artigo como ponto de partida, foi possível pensar sobre algumas questões.

A primeira delas é que por não haver uma espécie de diretriz para a criação de uma cidade, a existência de pré-requisitos, os diferentes agentes escreveram o que, para os seus entendimentos, seriam aspectos relevantes para sensibilizar o Príncipe Regente na obtenção da almejada "graça”. Na realização deste esforço, eles acabaram por revelar as representações de cidades que possuíam, dentro do contexto da época.

Essas representações refletiam as visões de mundo dos diferentes grupos participantes da dinâmica imperial e que, naquele momento, viviam na África Oriental Portuguesa. Temos o ponto de vista do governador-geral, um funcionário régio enviado para Moçambique para realizar uma tarefa por um período determinado. Em julho de 1800, havia quase três anos que ele estava na capitania desenvolvendo sua função. Era esse o seu tempo de conhecimento e de entrosamento com a realidade moçambicana. Os membros da câmara eram pessoas da elite local, indivíduos com predicados considerados especiais e que os autorizavam a representar o conjunto da população. ${ }^{47}$ Por serem indivíduos nascidos na capitania, ou lá residentes algum tempo, traziam consigo anseios e pontos de vista particulares perante à administração central. Já o religioso, um homem natural de Portugal, e que como o governador-geral, encontrava-se em Moçambique durante um tempo específico. Quando o Bispo de Pentacomia escreveu sua carta, já havia, aproximadamente, 19 anos que ele estava em Moçambique. Podemos considerar que quase duas décadas constroem uma boa base de experiência e de conhecimento sobre a realidade local. Refira-se que, além das atividades de caráter religioso, o

\footnotetext{
${ }_{46}^{46}$ "Carta de Lei elevando à categoria de cidade a villa de Moçambique, de 17 de Setembro de 1818" In Boletim do Conselho Ultramarino, Legislação Antiga, Vol. II (1755 a 1834). Lisboa, Imprensa Nacional, 1867, p. 352-353.

${ }^{47}$ Ainda que tenham assumido algumas particularidades de acordo com o espaço onde estavam instaladas, as câmaras municipais do Império Português tinham um elo em comum: a sua composição, ou melhor, a "qualidade daqueles passíveis de representarem e se fazerem representar". Os predicados gerais assumidos pelos indivíduos aptos à participação nas câmaras podiam ser circunscritos nas expressões "homens bons", para o contexto da América Portuguesa. Nas terras do lado atlântico, o termo dizia respeito àqueles "indivíduos de reconhecida posição social", devendo ser "naturais da terra e da governança dela, ou houvessem sido seus pais, e avós, de idade conveniente e sem raça alguma" (BOXER, op. cit., p. 264).
} 
dominicano igualmente participou das atividades político-administrativas da capitania. Entre os anos de 1783 e 1786, junto com António José de Morais Durão (ouvidor-geral) e Vicente Caetano da Maia e Vasconcelos (tenente-coronel), integrou o governo provisório da capitania. Ou seja, as três cartas, ao mesmo tempo que permitiram conhecer determinados aspectos da África Oriental Portuguesa, também revelaram as aspirações dos diferentes grupos envolvidos naquele cotidiano.

Em razão do pertencimento desses indivíduos à determinados grupos participantes da dinâmica imperial e dos seus arcabouços culturais, as imagens construídas nas correspondências não foram homogêneas. O governador-geral, por exemplo, investiu na argumentação sobre a importância da população. Mas, ao mesmo tempo, é interessante o esforço que Meneses da Costa empreendeu para desfazer uma representação que pairava sobre a capitania, a insalubridade do território. A partir do que ele escreveu, assim como por alguns comentários feitos pelos membros da câmara, notou-se o emprenho do governador-geral na construção de um discurso oposto, valorizando a salubridade do lugar e o consequente benefício que ela trazia para a saúde da população.

Os membros da câmara deram um pouco mais de ênfase à estrutura urbana da vila, procurando exaltar o "esplendor" do lugar. Em certa medida, havia uma "tradição de inscrição urbana"48 que caracterizava a configuração das cidades. Nesse sentido, podemos entender a escolha desta temática no repertório dos motivos apresentados pelos juiz, vereadores e procurador da câmara. Não nos interessou o mérito dessa questão, se a vila de Moçambique era um aglomerado urbano modesto ou grandioso. O que nos importou perceber foi a construção de uma imagem que os autores das cartas acreditavam que sensibilizaria o Príncipe Regente para que o objetivo fosse atendido. ${ }^{49}$

A elevação da vila de Moçambique em cidade traria benefícios de caráter simbólico. As três cartas, consideradas representantes dos anseios de grupos distintos, revelaram expectativas de promoção de status social, tanto do território como dos agentes envolvidos. Conforme argumentou Cláudia

\footnotetext{
${ }^{48}$ DOMINGOS, Nuno; PERALTA, Elsa. Cidades e Império. Dinâmicas coloniais e reconfigurações pós-coloniais. Lisboa, Edições 70, 2013, p. XVI.

${ }^{49}$ Como procuramos argumentar ao longo do texto, estamos lidando com representações, com imagens construídas pelos autores das correspondências. Deve-se estar ciente que a documentação administrativa sobre a capitania de Moçambique e Rios de Sena também revela outros quadros, outras imagens. Por vezes elas foram semelhantes, por vezes foram contraditórias. Um exemplo nesse sentido foram os comentários sobre o desenvolvimento econômico da vila, sobre a presença de uma população europeia católica, e a ideia de salubridade do território.
} 
Fonseca, no já referido estudo sobre a concessão dos títulos de vila e cidade para as povoações de Minas Gerais, "as qualidades e os títulos das aglomerações [urbanas] podiam ajudar as elites locais a obter honras e privilégios: vários exemplos mostram que estes eram, de fato, mais facilmente atribuídos aos camaristas de uma cidade do que aos de uma vila". ${ }^{50}$ Em relação a um provável prestígio do território, talvez a mudança de estatuto (de vila para cidade) trouxesse maior visibilidade daquela localidade no interior do próprio Império Português, tornando-a mais conhecida, ou quem sabe mais respeitada na dinâmica administrativa.

Como já mencionado, as diligências empreendidas pelas distintas autoridades instaladas em Moçambique não resultaram no pronto atendimento de mudança de estatuto daquela localidade. Todavia, o propósito do artigo não foi averiguar se o esforço realizado por esses homens obteve o êxito desejado ou não. Mas, sim, conhecer o processo no qual autoridades locais argumentavam e justificavam quando da solicitação de um título de cidade. 0 pedido encaminhado pela vila de Moçambique revelou um quadro complexo, tratando-se de uma ação coordenada por distintas instâncias de poder domiciliadas na sede do governo da África Oriental Portuguesa. A ênfase na escrita do governador-geral, dos membros da câmara e do religioso nos mostraram, ao mesmo tempo, as suas expectativas quanto à mudança do estatuto da vila, as suas representações de cidade e as formas como cada um desses sujeitos se relacionava com as diferentes esferas integrantes do Império Português. Nesse sentido, acreditamos ter realizado um exercício de compreensão de um tema (elevação de uma vila à categoria de cidade) dentro de escalas de análise que transitaram em termos locais (vila de Moçambique) e em um contexto global, delimitado pelas dinâmicas do Império Português.

Artigo recebido para publicação em 21/04/2018 Artigo aprovado para publicação em 04/07/2018

${ }^{50}$ FONSECA, op. cit., p. 43. 